\title{
Rubin H. Flocks and Colloidal Gold Treatments for Prostate Cancer
}

\author{
Henry M. Rosevear ${ }^{1}$, Andrew J. Lightfoot ${ }^{1}$, Michael A. O’Donnell ${ }^{1}$, \\ Charles E. Platz ${ }^{2}$, Stefan A. Loening ${ }^{3}$, and Charles E. Hawtrey ${ }^{1, *}$ \\ ${ }^{1}$ Department of Urology, University of lowa, lowa City; ${ }^{2}$ lowa Cancer Registry, lowa \\ City; ${ }^{3}$ Humboldt University, Charité Hospital, Berlin, Germany
}

E-mail: charles-hawtrey@uiowa.edu

Received March 3, 2011; Revised July 20, 2011; Accepted August 3, 2011; Published August 16, 2011

In the early 1950 s, Rubin H. Flocks of the University of lowa began to treat prostate cancer patients with colloidal gold $\left(\mathrm{Au}^{198}\right)$ therapy, evolving his technique over nearly 25 years in 1515 patients. We reviewed the long-term outcomes of Flocks' prostate cancer patients as compared to those patients treated by other methods at the University of lowa before Flocks' chairmanship. We reviewed archived patient records, Flocks' published data, and long-term survival data from the lowa Tumor Registry to determine short- and long-term outcomes of Flocks' work with colloidal gold. We also reviewed the literature of Flocks' time to compare his outcomes against those of his contemporaries. The use of colloidal gold, either as primary or adjunctive therapy, provided short- and long-term survival benefit for the majority of Flocks' patients as compared to historical treatment options $(p<0.001)$. Flocks' use of colloidal gold for the treatment of locally advanced prostate cancer offered short- and long-term survival benefits compared to other contemporary treatments.

KEYWORDS: prostate cancer, survival, gold colloid, urology, anatomy, history of medicine

\section{INTRODUCTION}

While interstitial implantation of radioactive materials into tumors had been explored for several decades, interest in its widespread clinical application grew when Rubin H. Flocks introduced the instillation of colloidal gold $\left(\mathrm{Au}^{198}\right)$ into the prostate and its environs during open prostate operations. In 1951, Flocks instilled $60 \mathrm{mCi}$ of colloidal $\mathrm{Au}^{198}$ into the prostate of an 80 -year-old man with prostate cancer refractory to estrogen therapy[1]. This patient's dramatic reduction in prostate volume became the index case for a series of 1515 men treated with colloidal gold over the next 25 years. While Flocks did not live to see his survival data mature, the University of Iowa Hospitals and Clinics' Cancer Registry and the Iowa State Tumor Registry have allowed us to review his extensive series and report on the evolution of Flocks' treatment philosophy, complications, and success in the era before early prostate cancer diagnosis with prostate-specific antigen. 


\section{THE EVOLUTION OF FLOCKS' COLLOIDAL GOLD TREATMENT}

The lack of any effective screening tool in the early part of the $20^{\text {th }}$ century, other than digital rectal exam, meant that prostate cancer presented in a very different manner than is common today. Over $90 \%$ of patients seen at the University of Iowa in the 20 years preceding Flocks' work with colloidal gold presented with symptoms of either locally advanced or metastatic disease, usually with urinary obstruction[2]. In 1950, Flocks was confronted with an 80-year-old gentleman with hormonally resistant, locally extensive prostate cancer. Retropubic placement of radon seeds was planned, but was complicated mid-operation when it was discovered that the seeds were not available. Flocks immediately substituted $60 \mathrm{mCi} \mathrm{Au}{ }^{198}$ colloid injected into the cancer tissue. The gold colloid was readily available at the institution as it was undergoing use for palliation of intraperitoneal metastases in ovarian cancer patients[3]. At 1.5 years' follow-up, the patient's prostate had reduced to normal size.

Earlier reports of successful prostate cancer treatment with radium implantation were complicated by an association with severe bowel and bladder irritation and ulceration[2]. Flocks theorized that colloidal gold would allow more localized radiation with less risk to adjacent structures, while dramatically increasing the local dose of radiation because of the shorter half-life and beta penetration of colloidal gold as compared to radium. Flocks also theorized that some of the radioactive gold would be transported to the draining lymph nodes, where it could treat metastatic spread of the disease.

Flocks reported his initial 20 cases of interstitial radiation with radioactive gold in 1952[1]. His technique involved a combined retropubic and intravesical approach, to maximize exposure to the prostate, seminal vesicles, and regional lymph nodes. While the majority of the radiation from colloidal gold is from a short-lived and short-traveling beta ray, gamma radiation, with its greater ability to penetrate tissue and travel long distances, created the potential for significant whole-body radiation if given in large doses. Thus, Flocks' original dosing approximated $3 \mathrm{mCi}$ per estimated gram of tissue in glands weighing $<25 \mathrm{~g}$ and $1 \mathrm{mCi}$ per estimated gram of tissue for prostates weighing $>150 \mathrm{~g}$. While no long-term data were available to Flocks at the time of his 1952 publication, he reported that in 17 of 20 cases, all palpable prostatic firmness had resolved within weeks, while significant improvement was seen in the remaining three cases.

In 1955, Flocks reported on his first 100 cases of colloidal gold therapy, noting some changes in his operative technique[4]. These patients were carefully screened so that only those with locally advanced disease would receive gold therapy; patients with metastatic disease were excluded. Of his first 50 patients, 18 developed rectal irritation, eight of whom eventually suffered rectal ulcerations, including four who required a colostomy. To understand this tragic complication, Flocks spent time in the anatomy lab and soon discovered that the large volumes of colloidal gold he was using (up to $100 \mathrm{cc}$ ) were spreading along Denonvillier's fascia, resulting in excess radiation to the rectum. By reducing the volume of gold colloid instilled, but not the millicurie content of the solution, he noted no rectal complications in his second group of 50 patients. He also reported efforts to ensure good distribution throughout the prostate using hyaluronidase with the colloidal gold. Flocks advocated repeat perineal injections weeks after the initial surgery if the patient's clinical picture (based on reduction in prostate mass) did not improve. At 2 years' follow-up, 46 of the first 100 treated patients were alive.

After the first 100 cases, the pace of Flocks' work increased and by 1957, he had performed 389 total cases[5]. He reported again that the most challenging issue in his technique was adequate distribution of the radioactive gold throughout the prostate. He used postinjection radiation scans to evaluate the distant spread of the colloidal gold. His next publication reported on his outcomes with 785 procedures in his first 517 patients treated with a range of one to seven injections of colloidal gold per patient based on clinical response[6]. He settled on a concentration of $1-1.5 \mathrm{mCi} \mathrm{Au}{ }^{198}$ per gram of prostate tissue $(\sim 100$ $\mathrm{mCi}$ ) diluted in a volume of 2-4 cc. He also described further surgical modifications, including transitioning to the standard removal of the regional pelvic lymph nodes regardless of their gross appearance whenever feasible. He based this decision on the overall increased survival he found in patients with negative lymph nodes. He also described in detail the complications resulting from his procedure. Four patients died while in hospital following the procedure. A review of the autopsy records 
showed that two died of myocardial infarction and two died of pulmonary embolism. Of note, the careful attention to injected volume appeared to have significantly lowered the rectal ulceration complication risk from $16 \%$ in the first 50 patients to $0.5 \%$ in the next 467 .

In a separate publication in 1958, Flocks described his first 5-year outcomes[7]. This cohort included 135 patients and an interesting caveat. In referring to his overall outcome of $34 \%$ survival, Flocks stated, "It must be remembered, however, that many of the early patients were old, decrepit, and so riddled with intercurrent disease that they succumbed to these conditions rather than to prostatic cancer." This 5-year survival compared well against the $18 \%$ historical 5-year survival at the University of Iowa before the introduction of colloidal gold therapy. In reporting his outcomes in this group, he separated his patients by prostate size. In the $<20$ g group, 10 of 11 patients (91\%) were alive, whereas only two of $20(10 \%)$ with glands $>100 \mathrm{~g}$ were alive. Flocks theorized that gland size was a surrogate marker for extent of disease and that his treatment was best for smaller-volume disease. This theory is supported by long-term data. Using survival data from the Iowa Tumor Registry in combination with prostate size as reported in Flocks' 1959 paper on lymphatic spread of prostate cancer[8], the Kaplan-Meier curve shown in Fig. 1 demonstrates a significant difference in survival based on prostate size.

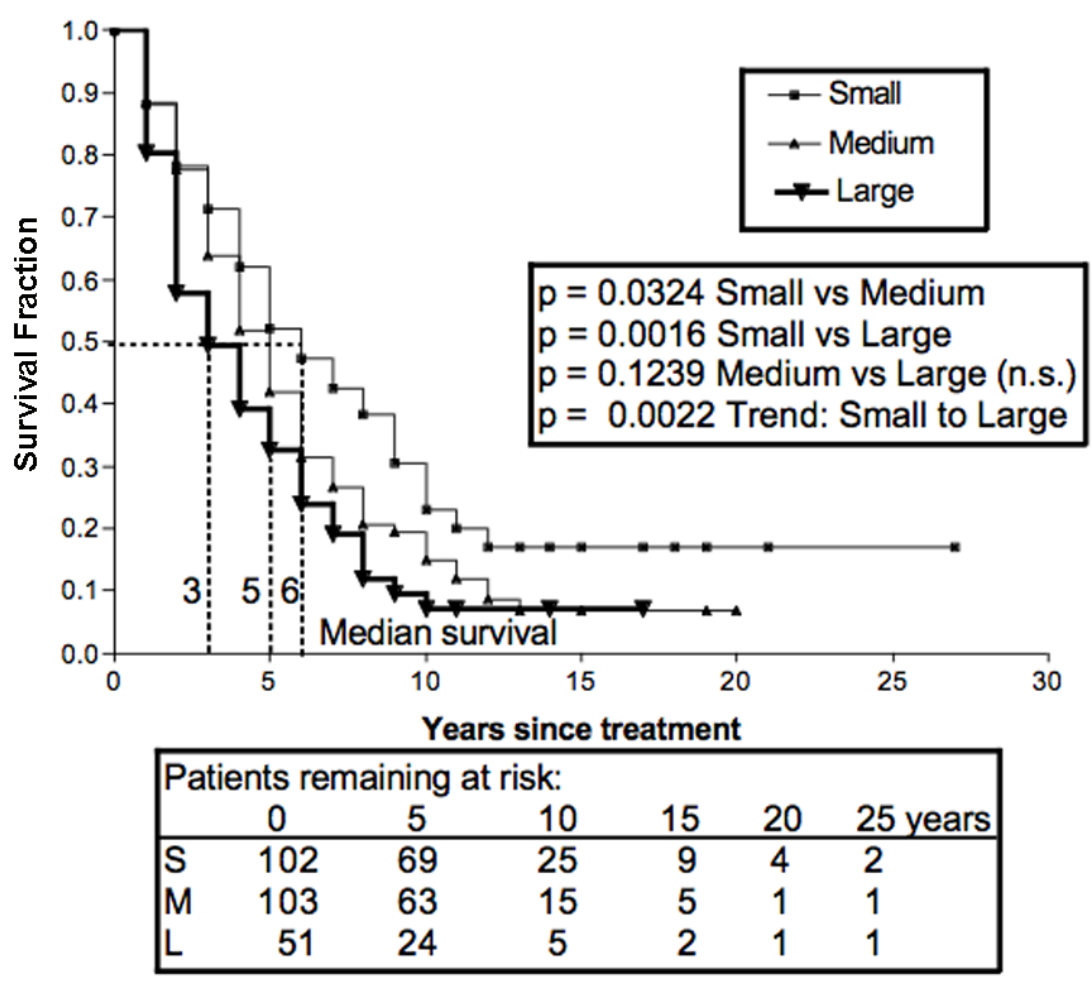

FIGURE 1. Flocks prostate cancer gold therapy, disease-specific survival comparison by prostate size.

Flocks later reported his experience combining colloidal gold treatment with radical prostatectomy for stage C lesions[9,10]. Stage C, by definition, invades the capsule and partially invades the areolar tissue around the prostate itself and around the base of the seminal vesicles, but has no evidence of metastatic or lymph node extension. In a series of 335 such patients with 5-year follow-up, Flocks reported a $4.4 \%$ local recurrence rate, which was dramatically lower than the $21-28 \%$ recurrence rate that was being reported by his contemporaries who were treating the disease with radical prostatectomy alone[11]. 
By 1969, Flocks had treated 1074 patients in over 1500 separate procedures[12]. He had concluded by this point that if the volume of the prostate was $>40 \mathrm{~g}$, cure using only colloidal gold was not possible because of distribution problems necessitating the use of surgery for curative intent. He also recommended repeat injections at 2 months, either transrectally or transperineally, to destroy any residual tumor.

Flocks' last paper on his experience with colloidal gold was published in 1973, in which he reviewed his long-term survival data on patients with stage $C$ disease[13]. It was his practice in cases of locally advanced disease to remove the prostate if possible and then apply colloidal gold to the surrounding tissue, and, when the prostate could not be removed, he used electrodessication of the prostatic tissue and seminal vesicles to decrease the tumor mass and then instilled the radioactive colloidal gold into the tissue. He reported a 27.5\% 15-year survival for patients with stage $\mathrm{C}$ disease who were lymph node negative at the time of surgery. This was equivalent to the results being reported by his contemporaries for stage A (occult disease) or stage B disease (confined to the prostate) treated with surgery alone[14].

\section{LONG-TERM OUTCOMES}

Flocks, like all surgeon scientists, was interested in translating modern science into better clinical outcomes for his patients. In the era before colloidal gold treatment, the 5-year survival for patients with prostate cancer was between 18 and 27\%, based on Flocks' own review of 854 patients treated at the University of Iowa and a similar series of 504 patients at the University of Michigan[15]. The use of colloidal gold at the University of Iowa ended in 1975 soon after Flocks died, when the colloidal version of $\mathrm{Au}^{198}$ was replaced with $\mathrm{Au}^{198}$ radioactive seeds by the manufacturer. To investigate the long-term outcomes of Flocks' colloidal gold therapy for prostate cancer, the Iowa Tumor Registry examined the outcomes of all patients treated at the University of Iowa under Flocks' care. A Kaplan-Meier analysis comparing all of the patients Flocks treated with colloidal gold to the two series mentioned above demonstrates significant improvement in overall survival for the gold-treated patients $(p<0.001$, Fig. 2$)$. It is important to remember that Flocks was treating patients with locally advanced disease - T3/T4 by today's staging system. Flocks divided his patients into two categories based on whether he could safely remove the prostate. He would perform a prostatectomy if possible, then apply the colloidal gold to the area immediately around the bed of the prostate; if prostatectomy was not possible, he would inject the colloidal gold into the prostate itself. An analysis of these two groups shows a significant survival benefit for those patients in whom prostatectomy was performed $(p=0.05$, Fig. 3$)$, while all three groups did better than either of the historical controls mentioned above ( $p=0.001$, figure not shown).

A final way to compare Flocks' success with prostatectomy and colloidal gold is to compare his longterm survival outcomes to those of his direct contemporaries[16,17,18]. A caveat that must be stated when comparing these data is that Flocks was the only surgeon in this comparison group who would operate with curative intent on patients felt to have locally advanced disease. The other three distinguished surgeons carefully selected their patients in order to minimize the chance of local extension. When comparing these groups, Flocks' cohort of all patients receiving gold fared the worst ( $p=0.001$, Fig. 4). Looking at only the Flocks patients who underwent total prostatectomy, gold therapy without concomitant orchiectomy (a surrogate marker for those Flocks patients with the least advanced disease), there is no significant difference in outcome between patients in all comparison groups. However, another group of patients still did significantly better $(p=0.05)$ [18].

As previously noted, Flocks' local recurrence rate was significantly lower than that of his peers, with reported rates of 28,29 , and 34\%, compared to Flocks' $17 \%$ overall recurrence rate[11,19,20], again suggesting a beneficial role for colloidal gold therapy. 


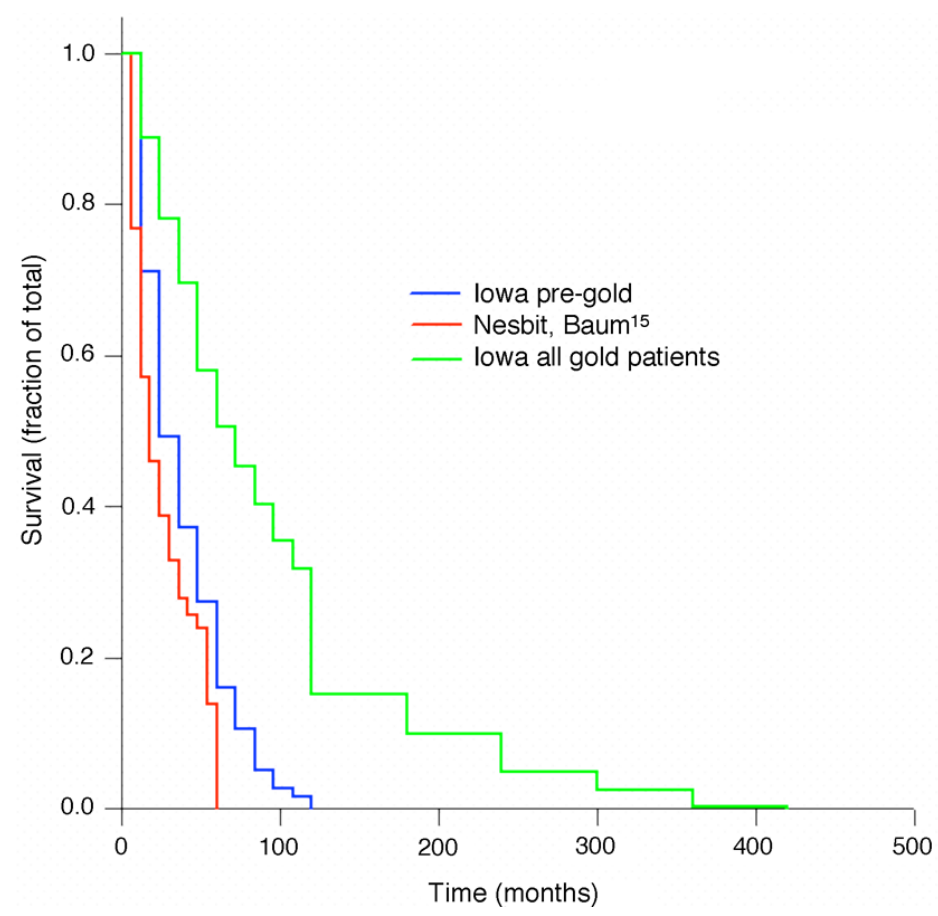

FIGURE 2. Survival analysis: Iowa prostate cancer patients pregold treatment vs. Iowa gold-treated patients vs. University of Michigan patients[15].



FIGURE 3. Survival analysis: Iowa prostate cancer patients treated with gold injection only vs. those treated with prostatectomy and gold injection. 


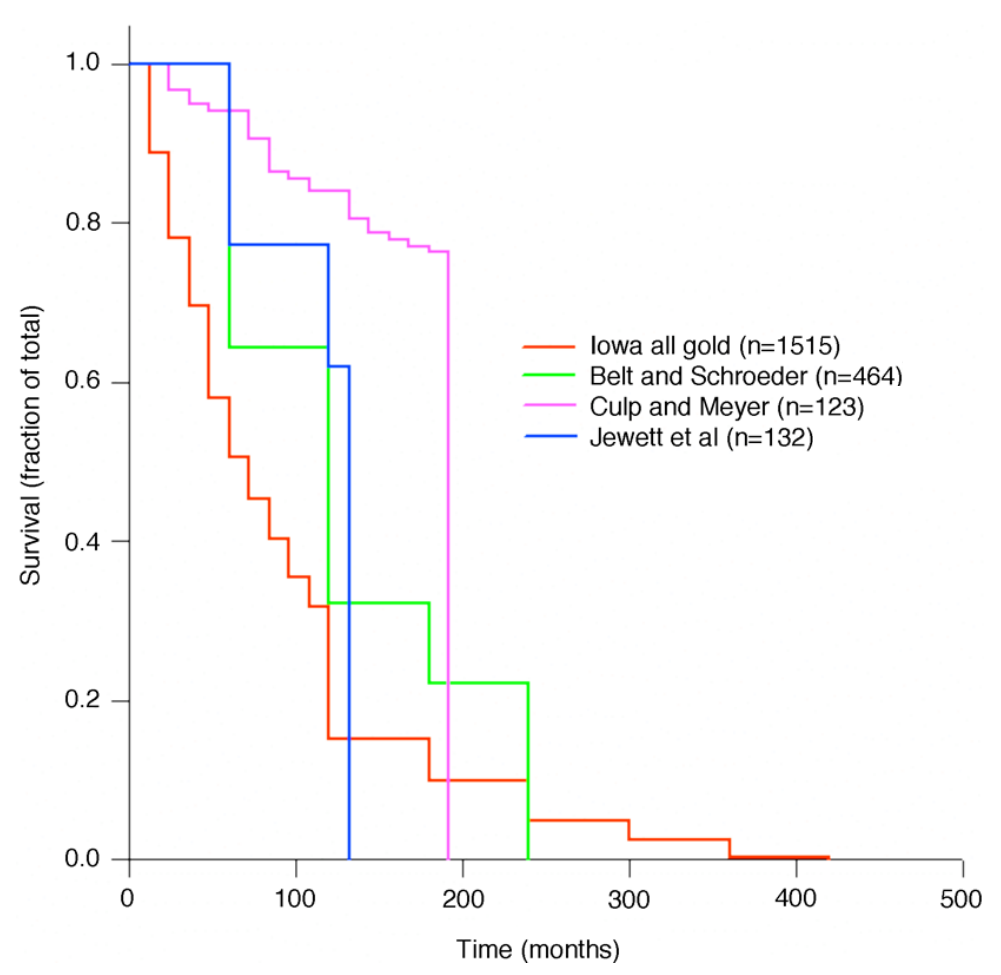

FIGURE 4. Survival analysis: all Iowa gold-treated patients vs. contemporary prostate cancer patient reported series[16,17,18].

It was hypothesized in the early literature on colloidal gold therapy that venous and lymphatic spread of the gold may increase the risk of lymphoma[2]. While Flocks made every effort to limit the total millicurie injection content, theoretical and actual concerns over whole-body gamma radiation leading to other secondary malignancies also existed. Thus, we also reviewed the available data on all secondary malignancies of patients treated with colloidal gold (Table 1). No significant differences were noted in the number of cases of lymphoma or four other common cancers, suggesting that the two populations are similar in second primary risk. The only type of cancer to have statistically different incidence between Flocks' cohort and the rest of the general Iowa population was stomach cancer, where six cases $(0.4 \%$ of patients receiving gold therapy) were reported compared to 13 cases $(0.2 \%$ of the general Iowa population; proportional incident ratio of 2.62 CI 1.21-5.70).

\section{CONCLUSIONS}

Flocks' innovative use of colloidal gold over nearly 25 years resulted in statistically significant improvements in short- and long-term survival for his patients. He also helped to advance the understanding of lymph node staging for prostate cancer. He pioneered a multidisciplinary approach to prostate cancer treatment, drawing on the strengths of other radiation oncologists at the University of Iowa. His determination and continuous efforts at improving his techniques through basic science and anatomical research created a paradigm of translational research that is broadly used today. 


\section{TABLE 1}

\begin{tabular}{|c|c|c|c|c|c|c|}
\hline \multirow[b]{2}{*}{$\begin{array}{l}\text { Second } \\
\text { Cancer } \\
\text { Primary Site }\end{array}$} & \multicolumn{3}{|c|}{$\begin{array}{l}\text { Flocks' Colloidal Gold Patients, } \\
1951-1977\left(\mathrm{n}=1431^{*}\right)\end{array}$} & \multicolumn{3}{|c|}{$\begin{array}{c}\text { All lowa Resident Prostate Cancers, } \\
\qquad 1969-1975(\mathrm{n}=6168)\end{array}$} \\
\hline & $\begin{array}{c}\text { Number } \\
\text { Second } \\
\text { Primaries } \\
(\mathrm{n}=94)\end{array}$ & $\begin{array}{c}\text { All Au } \\
\text { Second } \\
\text { Primaries }\end{array}$ & $\begin{array}{c}\text { All Au } \\
\text { Prostate } \\
\text { Cancers }\end{array}$ & $\begin{array}{c}\text { Number } \\
\text { Second } \\
\text { Primaries } \\
(n=535)\end{array}$ & $\begin{array}{c}\text { All Au } \\
\text { Second } \\
\text { Primaries }\end{array}$ & $\begin{array}{c}\text { All } \\
\text { Prostate } \\
\text { Cancers }\end{array}$ \\
\hline Stomach & 6 & $6.4 \%$ & $0.4 \%$ & 13 & $2.4 \%$ & $0.2 \%$ \\
\hline Colon/rectum & 15 & $16.0 \%$ & $1.1 \%$ & 113 & $21.1 \%$ & $1.8 \%$ \\
\hline Pancreas & 5 & $5.3 \%$ & $0.4 \%$ & 20 & $33.7 \%$ & $0.3 \%$ \\
\hline Lung/bronchus & 20 & $21.3 \%$ & $1.4 \%$ & 97 & $18.1 \%$ & $1.5 \%$ \\
\hline Urinary bladder & 14 & $14.9 \%$ & $1.0 \%$ & 87 & $16.3 \%$ & $1.4 \%$ \\
\hline $\begin{array}{l}\text { Bone marrow/ } \\
\text { lymphoma }^{+}\end{array}$ & 9 & $9.6 \%$ & $0.6 \%$ & 93 & $17.4 \%$ & $1.5 \%$ \\
\hline All other sites & 25 & $26.6 \%$ & $1.7 \%$ & 112 & $20.9 \%$ & $1.8 \%$ \\
\hline
\end{tabular}

* $\quad$ For whom follow-up data are available.

$+\quad$ Leukemia, lymphoma, myeloma.

\section{REFERENCES}

1. Flocks, R.H., Kerr, H.D., Elkins, H.B., et al. (1952) Treatment of carcinoma of the prostate by interstitial radiation with radio-active gold (Au 198): a preliminary report. J. Urol. 68, 510-522.

2. $\quad$ Flocks, R.H., Harness, W.N., Tudor, J.M., et al. (1951) Treatment of carcinoma of prostate. J. Urol. 66, $393-407$.

3. Keettel, W.C. and Grant, R.N. (1966) The treatment of ovarian cancer. CA Cancer J. Clin. 16, $245-248$.

4. Kerr, H.D., Flocks, R.H., Elkins, H.B., et al. (1955) Follow-up study of one hundred cases of carcinoma of the prostate treated with radioactive gold. Radiology 64, 637-641.

5. Flocks, R.H., Elkins, H.B., and Culp, D. (1957) Treatment of cancer of prostate by interstitial injection of Au 198: studies in problem of distribution. J. Urol. 77, 505-520.

6. Flocks, R.H., Culp, D.A., and Elkins, H.B. (1959) Present status of radioactive gold therapy in management of prostatic cancer. J. Urol. 81, 178-184.

7. Elkins, H.B., Flocks, R.H., and Culp, D.A. (1958) Evaluation of the use of colloidal radioactive gold in the treatment of prostatic carcinoma. Radiology 70, 386-389.

8. $\quad$ Flocks, R.H., Culp, D., and Porto, R. (1959) Lymphatic spread from prostatic cancer. J. Urol. 81, $194-196$.

9. $\quad$ Flocks, R.H. (1968) Radiation therapy for prostatic cancer. J. Urol. 100, 680-682.

10. Flocks, R.H. (1972) The treatment of stage C prostatic cancer with special reference to combined surgical and radiation therapy. Trans. Am. Assoc. Genitourin. Surg. 64, 58-60.

11. Whitmore, W.F., Jr. (1963) The rationale and results of ablative surgery for prostatic cancer. Cancer 16, 1119-1132.

12. Flocks, R.H. (1969) Present status of interstitial irradiation in managing prostatic cancer. JAMA 210, 328-330.

13. Flocks, R.H. (1973) The treatment of stage C prostatic cancer with special reference to combined surgical and radiation therapy. J. Urol. 109, 461-463.

14. Jewett, H.J. (1969) The results of radical perineal prostatectomy. JAMA 210, 324-325.

15. Nesbit, R.M. and Baum, W.C. (1950) Endocrine control of prostatic carcinoma; clinical and statistical survey of 1,818 cases. JAMA 143, 1317-1320.

16. Belt, E. and Schroeder, F.H. (1972) Total perineal prostatectomy for carcinoma of the prostate. J. Urol. 107, 91-96.

17. Jewett, H.J., Bridge, R.W., Gray, G.F., Jr., et al. (1968) The palpable nodule of prostatic cancer. Results from 15 years after radical excision. JAMA 203, 403-406.

18. Culp, O.S. and Meyer, J.J. (1973) Radical prostatectomy in the treatment of prostatic cancer. Cancer 32, $1113-1118$.

19. Jewett, H. (1963) Treatment of early cancer of the prostate. JAMA 183, 373-375.

20. Belt, E. (1942) Radical perineal prostatectomy in early carcinoma of the prostate. J. Urol. 48, $287-297$. 
This article should be cited as follows:

Rosevear, H.M., Lightfoot, A.J., O’Donnell, M.A., Platz, C.E., Loening, S.A., and Hawtrey, C.E. (2011) Rubin H. Flocks and colloidal gold treatments for prostate cancer. TheScientificWorldJOURNAL: TSW Urology 11, 1560-1567. DOI 10.1100/tsw.2011.145. 


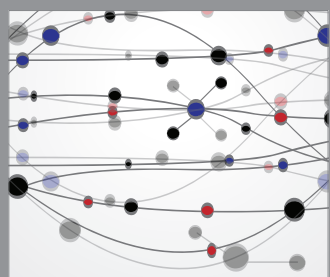

The Scientific World Journal
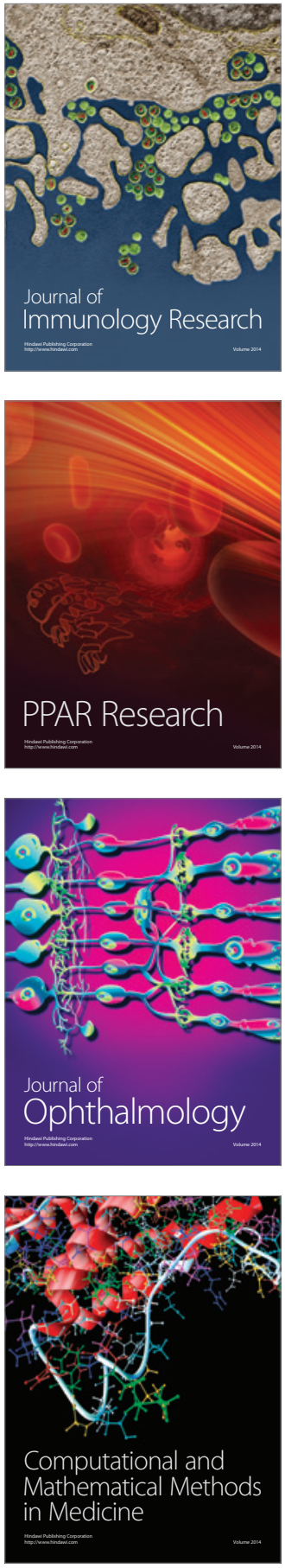

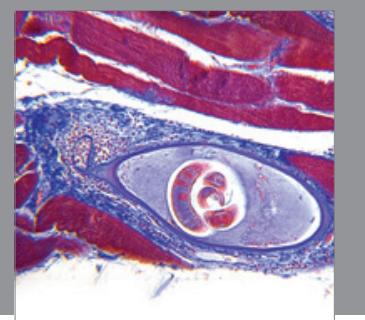

Gastroenterology

Research and Practice
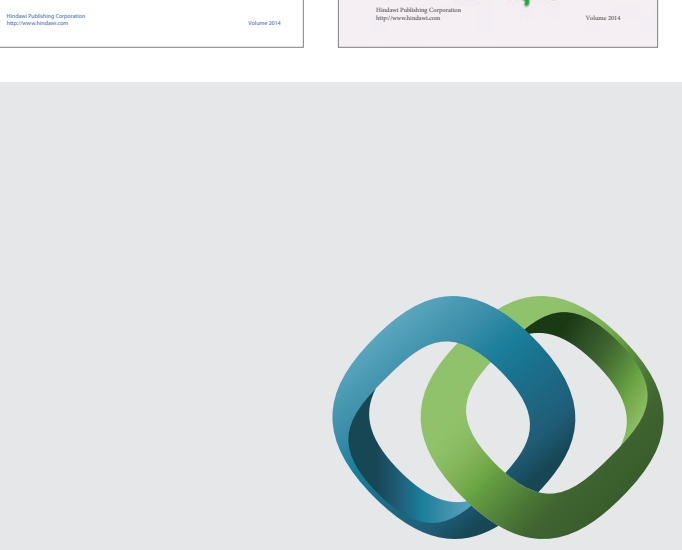

\section{Hindawi}

Submit your manuscripts at

http://www.hindawi.com
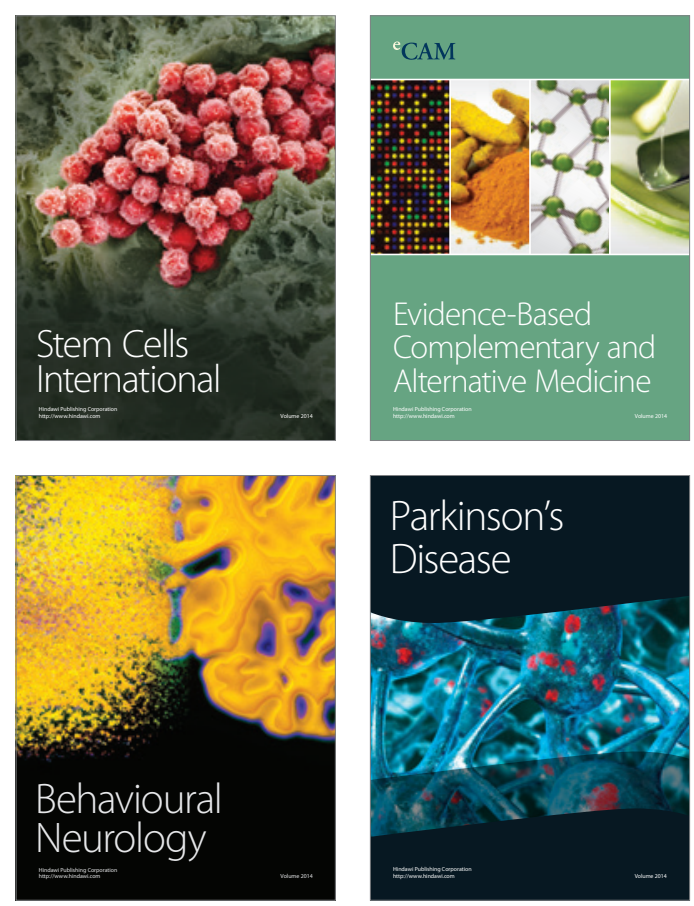

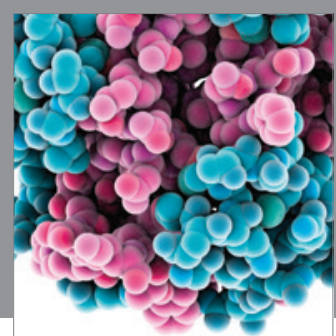

Journal of
Diabetes Research

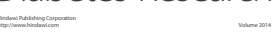

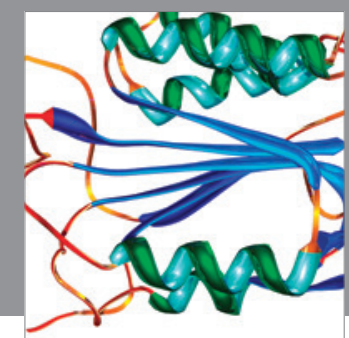

Disease Markers
